\title{
Successful Concurrent Chemoradiotherapy with Cisplatin plus Vinorelbine for Locally Advanced Thymic Carcinoma
}

\author{
Toshirou Fukushima $^{\mathrm{a}}$ Kazunari Tateishi $^{\mathrm{a}}$ Masayuki Hanaoka $^{\mathrm{a}}$ \\ Keiichirou Koiwai ${ }^{b}$ Shigeru Sasaki ${ }^{c}$ Tomonobu Koizumi ${ }^{c}$ \\ ${ }^{a}$ First Department of Internal Medicine, and Departments of ${ }^{b}$ Radiology and \\ ${ }^{c}$ Comprehensive Cancer Therapy, Shinshu University School of Medicine, \\ Matsumoto, Japan
}

\section{Key Words}

Thymic malignancy $\cdot$ Chemotherapy $\cdot$ Mediastinal tumor $\cdot$ Radiotherapy

\begin{abstract}
Little information is available about the usefulness of concurrent chemoradiotherapy for locally advanced thymic carcinoma due to a rare anterior mediastinal tumor. We experienced a case of locally advanced thymic carcinoma that responded well to concurrent thoracic radiotherapy combined with cisplatin plus vinorelbine chemotherapy. The patient showed remarkable tumor regression and has remained disease free for over 4 years following combined therapy. Concurrent chemoradiotherapy seems to be effective for locally advanced thymic carcinoma, and cisplatin plus vinorelbine could be an alternative chemotherapy regimen in combination with thoracic radiotherapy in patients with thymic carcinoma.
\end{abstract}

(C) 2014 S. Karger AG, Basel

\section{Introduction}

Thymic carcinoma is a thymic epithelial neoplasm with cytological malignant features and a clinical course that tends to be much more aggressive than that of thymoma [1,2]. Due to its rarity, however, the optimal therapy for advanced thymic carcinoma remains undetermined. In cases of locally advanced thymic carcinoma, a multimodality treatment including chemotherapy, surgery, and radiotherapy may improve the outcome [2-9].

Tomonobu Koizumi, MD

Department of Comprehensive Cancer Therapy

Shinshu University School of Medicine

3-1-1, Asahi, Matsumoto 390-8621 (Japan)

E-Mail tomonobu@shinshu-u.ac.jp 
Fukushima et al.: Successful Concurrent Chemoradiotherapy with Cisplatin plus Vinorelbine for Locally Advanced Thymic Carcinoma

Concurrent chemoradiotherapy is a strategy for unresectable disease. However, optimal chemotherapy combined with thoracic radiotherapy for locally advanced thymic carcinoma has been extremely limited because of the small numbers of reports about effective treatment [2-9]. Here, we describe a case of inoperable locally advanced thymic carcinoma successfully treated with concurrent radiotherapy with cisplatin plus vinorelbine chemotherapy.

\section{Case Report}

A previously healthy 53-year-old man was admitted to a local hospital because of an abnormality on chest radiography detected during health screening in October 2009. Chest computed tomography (CT) revealed an abnormal mass in the anterior and middle mediastinum (fig. 1). ${ }^{18} \mathrm{~F}$-fluorodeoxyglucose positron emission tomography (FDG-PET) showed positive uptake in the mediastinal mass and right supraclavicular lymph node (fig. 2). The patient suddenly developed hoarseness, and left recurrent nerve paralysis was detected. He was referred to our hospital for further examination. Physical examination and laboratory studies revealed no specific findings. Endobronchial ultrasound-guided transbronchial needle aspiration was performed for the mediastinal mass. The histological findings revealed undifferentiated type of carcinoma and the tumor cells were positive for CD 5. These findings were consistent with thymic carcinoma. Brain magnetic resonance imaging (MRI) revealed no brain metastasis. According to the classification of Masaoka et al. [10], the patient had advanced disease with supraclavicular lymph node metastasis (IVb).

Concurrent chemoradiotherapy was selected as treatment. The chemotherapy regimen consisted of cisplatin $\left(80 \mathrm{mg} / \mathrm{m}^{2}\right.$, day 1$)$ and vinorelbine $\left(25 \mathrm{mg} / \mathrm{m}^{2}\right.$, days 1 and 8$)$ every 4 weeks and concurrent thoracic radiation therapy ( 2 Gy $\times 30$ fractions, total 60 Gy). Partial response was achieved when 4 cycles of chemotherapy had been completed (fig. 3). He has remained well for approximately 4 years without any evidence of relapse.

\section{Discussion}

We reported our experience with successful concurrent chemoradiotherapy and cisplatin plus vinorelbine for locally advanced unresectable thymic carcinoma. Several case reports and series studies indicated the usefulness of concurrent chemoradiotherapy for locally advanced thymic carcinoma [2-9]. Platinum compounds are generally used in chemotherapy, but combined agents varied between reports. There have been frequent reports of the clinical usefulness of vinca alkaloids and etoposide [2-9]. On the other hand, with regard to studies on $>10$ thymic carcinoma patients to evaluate the efficacy of a single regimen, cisplatin, vincristine, doxorubicin, and etoposide or cisplatin, doxorubicin, vincristine, and cyclophosphamide showed relatively high response rates in metastatic advanced thymic carcinoma [11, 12]. These data suggested that thymic carcinoma is sensitive to chemotherapy. Thus, vinca alkaloids or etoposide are included in these regimens as an active agent against thymic carcinoma.

Vinorelbine is a newer semisynthetic vinca alkaloid and has greater activity than vindesine against metastatic non-small cell lung cancer (NSCLC). To our knowledge, there have been no previous reports regarding the combination of cisplatin plus vinorelbine with thoracic radiotherapy for the treatment of thymic carcinoma. Our experience suggests that 
Fukushima et al.: Successful Concurrent Chemoradiotherapy with Cisplatin plus Vinorelbine for Locally Advanced Thymic Carcinoma

cisplatin/vinorelbine is a useful chemotherapeutic regimen for concurrent thoracic radiotherapy in patients with thymic carcinoma.

Concurrent chemoradiotherapy with cisplatin and vinorelbine is a commonly used regimen for locally advanced NSCLC $[13,14]$. Naito et al. [13] demonstrated encouraging efficacy and safety of this therapy for inoperable stage III NSCLC. They reported a median survival time of 21 months and a 3 -year survival rate of $33 \%$. In addition, grade 3 or 4 adverse events of leukopenia were observed (67\%), but incidences of radiation pneumonitis and esophagitis were 6 and 4\%, respectively, which were apparently low compared with other reports. Thus, concurrent chemoradiotherapy with cisplatin and vinorelbine is highly active and well tolerated in lung cancer patients. Both cisplatin and vinorelbine may be expected to exert considerable synergistic interactions with concurrent radiotherapy [15]. Thus, concurrent radiotherapy could be performed with the administration of chemotherapeutic agents as radiosensitizers. Combined chemoradiotherapy may contribute to a better outcome and may be a valuable therapeutic tool for locally advanced thymic carcinoma. Thus, a novel regimen of chemotherapy suitable for thoracic radiotherapy is important for beneficial outcome and safety even in patients with thymic carcinoma.

Resectability of the remaining tumor following induction therapy may be an important issue in patients with locally advanced thymic carcinoma [2-9]. However, the residual tumor after chemoradiotherapy in the present case remained inoperable because of the involvement of large vessels. Based on several previous reports [2-9], chemoradiotherapy followed by surgery may contribute to a better clinical outcome in certain patients with locally advanced thymic cancer. Further clinical experience and studies are required.

In summary, the present case suggested that concurrent chemoradiotherapy is effective for locally advanced thymic carcinoma. In addition, vinorelbine is a novel agent with good activity against thymic carcinoma, which merits further clinical investigation as a chemotherapeutic option in patients with thymic carcinoma.

\section{Disclosure Statement}

The authors declare there are no potential conflicts of interest.

\section{References}

1 Suster S, Rosai J: Thymic carcinoma. A clinicopathologic study of 60 cases. Cancer 1991;67:1025-1032.

-2 Yano M, Sasaki H, Yokoyama T, Yukiue H, Kawano O, Suzuki S, Fujii Y: Thymic carcinoma: 30 cases at a single institution. J Thorac Oncol 2008;3:265-269.

-3 Greene MA, Malias MA: Aggressive multimodality treatment of invasive thymic carcinoma. J Thorac Cardiovasc Surg 2003;125:434-436.

4 Chen YY, Huang CH, Tang Y, Eng HL: Concurrent chemoradiotherapy for unresectable thymic carcinoma. Chang Gung Med J 2004;27:515-522.

-5 Rea F, Marulli G, Di Chiara F, Schiavon M, Perissinotto E, Breda C, Favaretto AG, Calabrese F: Multidisciplinary approach for advanced stage thymic tumors: long-term outcome. Lung Cancer 2011;72:68-72.

-6 Wright CD, Choi NC, Wain JC, Mathisen DJ, Lynch TJ, Fidias P: Induction chemoradiotherapy followed by resection for locally advanced Masaoka stage III and IVA thymic tumors. Ann Thorac Surg 2008;85:385389.

7 Shimono M, Hiraki A, Ueoka H, Tanimoto Y, Aoe M, Sakae K, Kaneda K, Sakugawa M, Kiura K, Harada M: Successful treatment with concurrent chemoradiotherapy followed by surgery for a patient with thymic adenocarcinoma. Anticancer Res 2001;21:2519-2522.

-8 Morio A, Nakahara K, Ohse Y, Tahara M, Goto T, Yakumaru K, Korenaga T: Efficacy of induction chemoradiotherapy in thymic cancer: report of a successful case and review of the literature. Int J Clin Oncol 2002;7:201-204. 


\section{Case Reports in Oncology}

\begin{tabular}{l|l}
\hline Case Rep Oncol 2014;7:65-69 & $\begin{array}{l}\text { C 2014 S. Karger AG, Basel } \\
\text { www.karger.com/cro }\end{array}$ \\
\hline DOI: $10.1159 / 000358380$ &
\end{tabular}

Fukushima et al.: Successful Concurrent Chemoradiotherapy with Cisplatin plus Vinorelbine for Locally Advanced Thymic Carcinoma

-9 Tagawa T, OHta M, Kuwata T, Awaya H, Ishida T: S-1 plus cisplatin chemotherapy with concurrent radiation for thymic basaloid carcinoma. J Thoracic Oncol 2010;5:572-573.

10 Masaoka A, Monden Y, Nakahara K, Tanioka T: Follow-up study of thymomas with special reference to their clinical stages. Cancer 1981;48:2485-2492.

11 Yoh K, Goto K, Ishii G, Niho S, Ohmatsu H, Kubota K, Kakinuma R, Nagai K, Suga M, Nishiwaki Y: Weekly chemotherapy with cisplatin, vincristine, doxorubicin, and etoposide is an effective treatment for advanced thymic carcinoma. Cancer 2004;98:926-931.

12 Agatsuma T, Koizumi T, Kanda S, Ito M, Urushihata K, Yamamoto H, Hanaoka M, Kubo K: Combination chemotherapy with doxorubicin, vincristine, cyclophosphamide, and platinum compounds for advanced thymic carcinoma. J Thorac Oncol 2011;6:2130-2134.

13 Naito Y, Kubota K, Nihei K, Fujii T, Yoh K, Niho S, Goto K, Ohmatsu H, Saijo N, Nishiwaki Y: Concurrent chemoradiotherapy with cisplatin and vinorelbine for stage III non-small cell lung cancer. J Thorac Oncol 2008;3:617-622.

14 Sekine I, Nokihara H, Sumi M, Saijo N, Nishiwaki Y, Ishikura S, Mori K, Tsukiyama I, Tamura T: Docetaxel consolidation therapy following cisplatin, vinorelbine, and concurrent thoracic radiotherapy in patients with unresectable stage III non-small cell lung cancer. J Thorac Oncol 2006;1:810-815.

-15 Fukuoka K, Arioka H, Iwamoto Y, Fukumoto H, Kurokawa H, Ishida T, Tomonari A, Suzuki T, Usuda J, Kanzawa F, Saijo N, Nishio K: Mechanism of the radiosensitization induced by vinorelbine in human nonsmall cell lung cancer cells. Lung Cancer 2001;34:451-460.
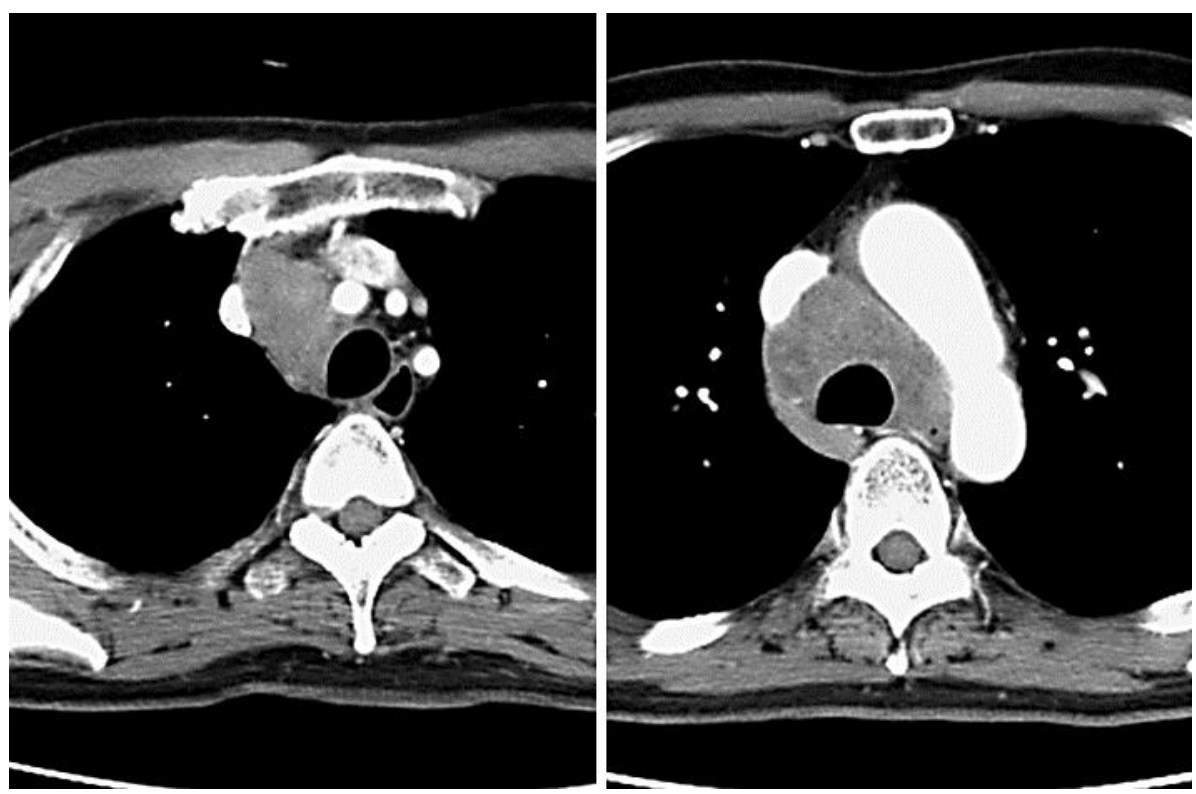

Fig. 1. Chest contrast-enhanced CT showed mediastinal tumor with lymph node enlargement surrounding the trachea. 
Fukushima et al.: Successful Concurrent Chemoradiotherapy with Cisplatin plus Vinorelbine for Locally Advanced Thymic Carcinoma

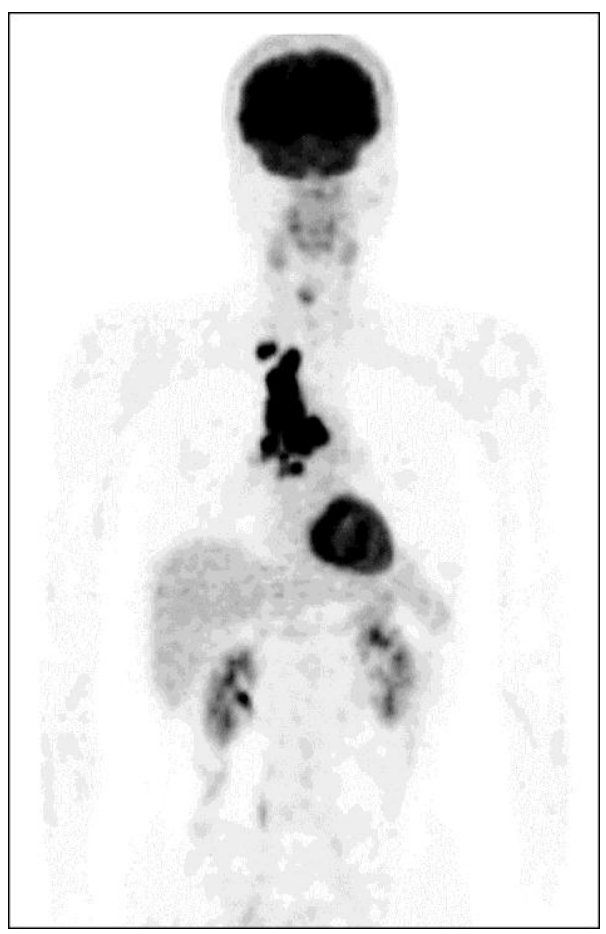

Fig. 2. FDG-PET before treatment revealed increased uptake in the mediastinal lesion and right supraclavicular lymph node.
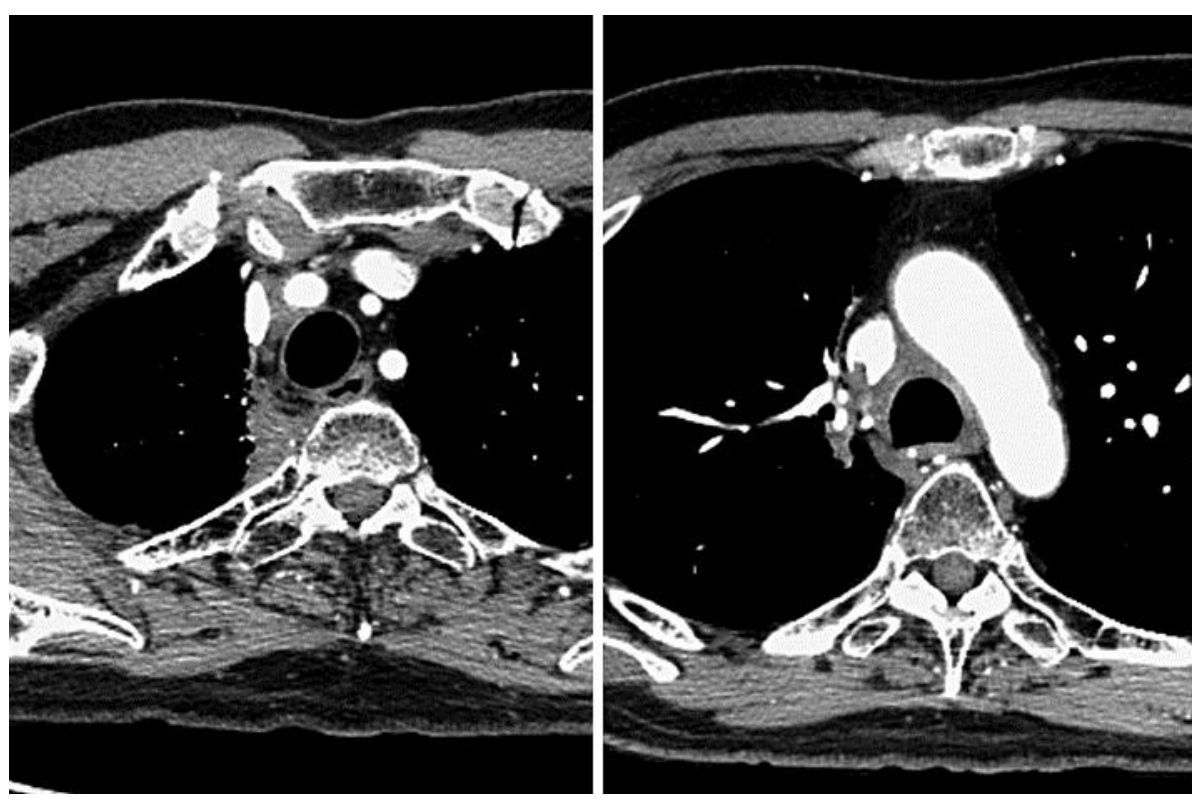

Fig. 3. Chest contrast-enhanced CT showed a reduced mediastinal mass after 4 cycles of chemotherapy and concurrent thoracic radiotherapy. 